Article

\title{
Conductometric Soot Sensors: Internally Caused Thermophoresis as an Important Undesired Side Effect
}

\author{
Gunter Hagen *, Christoph Spannbauer, Markus Feulner, Jaroslaw Kita, Andreas Müller \\ and Ralf Moos
}

Bayreuth Engine Research Center (BERC), Department of Functional Materials, University of Bayreuth, 95440 Bayreuth, Germany

* Correspondence: functional.materials@uni-bayreuth.de; Tel.: +49-921-55-7406

Received: 17 September 2018; Accepted: 15 October 2018; Published: 19 October 2018

\begin{abstract}
Particulate matter sensors are of interest for application in the exhaust of any combustion processes, especially for automotive aftertreatment systems. Conductometric soot sensors have been serialized recently. They comprise planar interdigital electrodes (IDE) on an insulating substrate. Between the IDEs, a voltage is applied. Soot deposition is accelerated by the resulting electric field due to electrophoresis. With increasing soot deposition, the conductance between the IDE increases. The timely derivative of the conductance can serve as a sensor signal, being a function of the deposition rate. An increasing voltage between the IDE would be useful for detecting low particle exhausts. In the present study, the influence of the applied voltage and the sensor temperature on the soot deposition is investigated. It turned out that the maximum voltage is limited, since the soot film is heated by the resulting current. An internally caused thermophoresis that reduces the rate of soot deposition on the substrate follows. It reduces both the linearity of the response and the sensitivity. These findings may be helpful for the further development of conductometric soot sensors for automotive exhausts, probably also to determine real driving emissions of particulate matter.
\end{abstract}

Keywords: particulate matter sensors; exhaust gas aftertreatment; particulate filter; soot deposition; electrophoresis; thermophoresis; dynamometer

\section{Introduction}

Fine dust and particulate matter (PM) emissions from combustion processes, especially from diesel combustion, may cause serious health problems. The exhaust gas aftertreatment of diesel engines becomes increasingly complicated due to tightening emission standards [1-3]. The determination of vehicle emissions during defined driving cycles on chassis dynamometers is going to be replaced by real-driving emissions measurements [4]. Therefore, prospective needs will concern reliable on-board measurement systems-also for PM [5,6].

Particle abatement with diesel particulate filters (DPF) is indispensable in future $[5,6]$. Additionally, in the field of gasoline fueled passenger cars, the PM issue may become even more serious, since nano-sized soot emissions have to be avoided [7]. In the past, particle mass was the key target, but recently, a particulate number limit has also been introduced. Therefore, gasoline particulate filters (GPF) have also been serialized [8,9]. In addition to that, on-board-diagnostics (OBD) has to ensure permanently the correct functionality of all exhaust gas aftertreatment systems, which is here the filtering efficiency of particulate filters [10-14].

For PM aftertreatment, as the current state-of-the-art, ceramic wall-flow filters are applied in the exhaust pipe. Soot from the raw exhaust is trapped over a certain time span, but the filter has 
to be regenerated during operation to avoid clogging. Therefore, soot load prediction models based on differential pressure sensors signals and engine characteristic maps are in serial use to estimate the filter loading state [12]. The more exactly the filter loading is known, the more efficiently the system can be operated. Filter regeneration at higher exhaust gas temperatures to burn off the trapped soot causes higher fuel consumption and should be carried out only when necessary $[15,16]$. A promising novel approach uses microwave sensors to determine directly the filter loading degree in operation [12,17-19].

For OBD-purposes, soot sensors are useful tools. Several principles are in the research or development state [20-26]. Conductometric (sometimes also called "resistive") soot sensors are very often discussed, in industry [20,27-29] and academia [30-33]. A typical sensor is sketched in Figure 1. This device is explained in detail, since it is also used for the experiments described below.

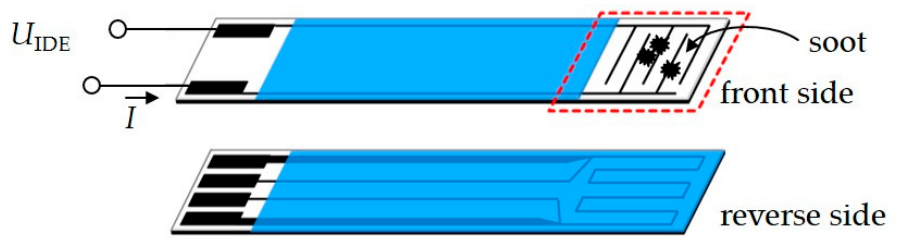

Figure 1. Sketch of the sensor setup: The sensors front side comprises interdigital electrodes (IDE) where soot deposits yield electrical conductive pathways over the spacing. On the reverse side, a four-wire thick-film heater allows temperature-controlled sensor regeneration as well as temperature measurement and temperature adjustment during soot deposition.

On the upper side of an insulating, high temperature stable alumina substrate, interdigital electrodes (IDE) are screen-printed with Pt paste (LPA88-11S, Heraeus, Hanau, Germany), dried and fired. The electrode area is about $5 \mathrm{~mm} \times 5 \mathrm{~mm}$ and comprises lines and spaces, both of $100 \mu \mathrm{m}$ width. On the reverse side of the substrate, a platinum thick-film structure is integrated. It is designed in a way that the temperature distribution on the sensor side is homogenous, if one uses the platinum thick-film structure as a heater [34]. Since it is designed in a special four-wire technique, the tip resistance can be measured and the temperature can be deduced from the tip resistance. The (almost linear) correlation function between heater resistance and sensor temperature is calibrated for each sensor in the lab before using the device. The heater structure provides two different functionalities. Firstly, it can be used for heating, i.e., for generating a homogenous temperature distribution in the IDE area either to regenerate the sensor surface by oxidation of soot at high temperatures $\left(600^{\circ} \mathrm{C}\right)$ or to heat the sensor tip to a desired temperature. Secondly, it enables measuring the sensor temperatures during soot deposition, which is, in fact-if only a very small heater current is applied-also a measurement of the actual exhaust gas temperature. All feed lines as well as the heater structure are covered by a glass ceramic passivation (QM 42, DuPont, CCI Eurolam, Dreieich, Germany) to avoid interconnections by soot particles. More details on the sensor setup can be found in previous publications [35,36].

Several modifications, especially for serial applications, have been reported in literature [20,26-29,31,32]. Not depending on the manufacturer or research lab, most of the conductometric soot sensors are operated similarly. By applying a voltage $U_{\text {IDE }}$ to the IDEs, an electrical current $I$ can be measured as soon as the deposited soot particles form a first electrical conductive percolation path between these electrodes. After this blind time, with proceeding soot deposition, the current increases. In other words, the sensor is an integrating device following the dosimeter principle with an instantaneous electrical readout, as described in [37]. During a subsequent regeneration, the sensor is heated to several hundred ${ }^{\circ} \mathrm{C}$ to burn off the soot. When cooled down to ambient temperature, i.e., to exhaust temperature, a new measurement cycle can start, again beginning with a blind time. In addition to a conductometric readout, capacitive measurements have also been investigated [23,24]. A typical operation mode of a conductometric soot sensor is described in Figure 2. 


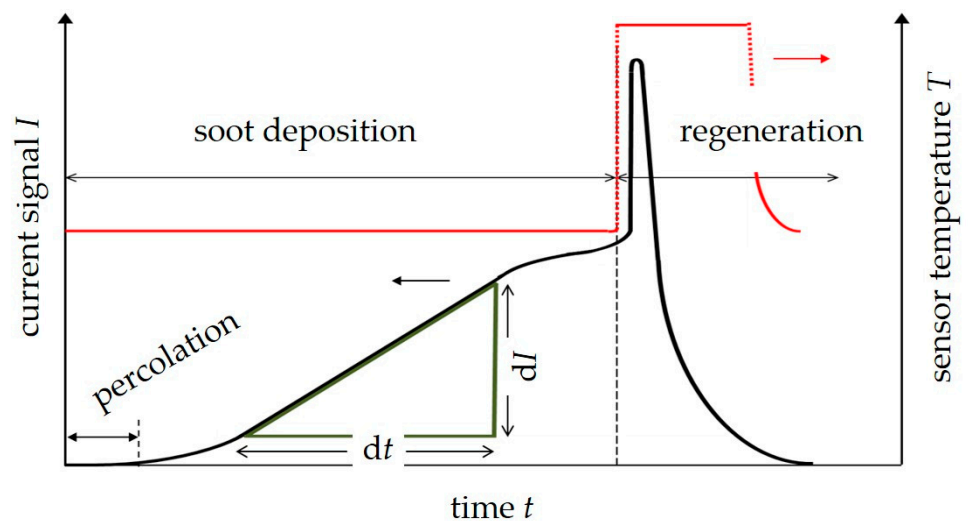

Figure 2. Typical shape of the sensor's raw signal during one sensing cycle with increasing current $I$ after a certain "blind" time before the percolation threshold is reached and a regeneration peak after increasing the sensor's temperature for soot burn off. The regeneration peak is due to the increased soot conductivity when heating up. The slope of the linear increasing current during soot deposition, which is proportional to the conductance, often acts as the sensor signal.

In our former work, we already showed the possibility for soot mass flow detection with these dosimeter-like conductometric sensors. A direct relation between the soot mass flow in the raw exhaust of a diesel engine and the timely derivative of the current $(\mathrm{d} I / \mathrm{d} t)$ between the IDE when a constant voltage is applied was found $[35,36]$.

In several contributions, the influence of the applied voltage was already found to be a significant parameter for soot deposition. Higher electrical fields interact with the charged soot particles. Another option is that electrical charges might be induced by the electrical field. Anyway, the soot is accelerated to the sensor's surface by the Coulomb forces and thus soot collection is enhanced electrophoretically [38-43]. However, in order to reliably determine particulate mass or particle number, a deeper understanding of the deposition mechanisms on the sensor surface is needed.

Soot is a highly complex matter. Characteristics like morphology, carbon content, adhered volatile organic components content or water, or its electrical charge will also influence the interaction with a measuring device [7,44-49]. For a further knowledge-based development of conductometric soot sensors, the influences of the applied voltage and of the sensor temperature on the soot deposition needs to be investigated. In order to keep flexibility with changing geometries, electrode designs, sensor orientations, housings, or to even be able to manufacture planar capacitive devices [24], we used our own sensor structure as shown in Figure 1. It is fully manufactured in thick-film technology, which is very close to typical production type sensors $[27,28]$. It is expected that our findings can be transferred to commercial sensors as well.

\section{Sensor Design and Experimental Setup}

It is the intention of the present study to contribute to a better understanding of factors that influence soot deposition on such sensors. Therefore, simple conductometric sensor devices were built as shown in Figure 1 and operated as explained above. In addition to that, in some experiments, the platinum film structure is used to adjust a defined temperature on the sensor tip, i.e., on the IDE, during soot deposition. Here, the sensor temperature is set to a few degrees higher than the exhaust gas temperature to study thermophoresis effects. The results are reported in the second part of this study.

After wiring and housing, the sensors were mounted into the exhaust pipe. Here, the sensors either face the gas flow with its IDE area or are oriented in a way that the sensor is mounted exactly perpendicular to the exhaust flow with the electrode area being behind the substrate in the shadow zone. No protection caps were used for these experiments. The sensor current and other parameters like heater resistance, applied voltage between the IDE $\left(U_{\mathrm{IDE}}\right)$, or heater voltage and heater current 
during active heating were recorded with a digital multimeter (2700 series, Keithley, Tektronix, Munich, Germany).

Experiments in the dynamometer test bench, i.e., in real exhausts, were conducted in the exhaust pipe of a $2.1 \mathrm{~L}$ diesel engine (Figure 3). To change the amount of soot during operation, the boost pressure $p_{\text {boost }}$ was varied between 1.25 bar and 1.15 bar. All other engine parameters were kept constant (1000 rpm, 25\% accelerator pedal position, injection pressure $p_{\text {inj }}=550$ bar). Most of the tests were conducted several times at different days to get an idea of the repeatability of the soot generation and to distinguish scattering (coming from soot concentration variations) from signal changes (resulting from the influencing parameters to be investigated). Particle concentration data were obtained by a commercial soot nanoparticle measurement device (Pegasor) simultaneously during all experiments.

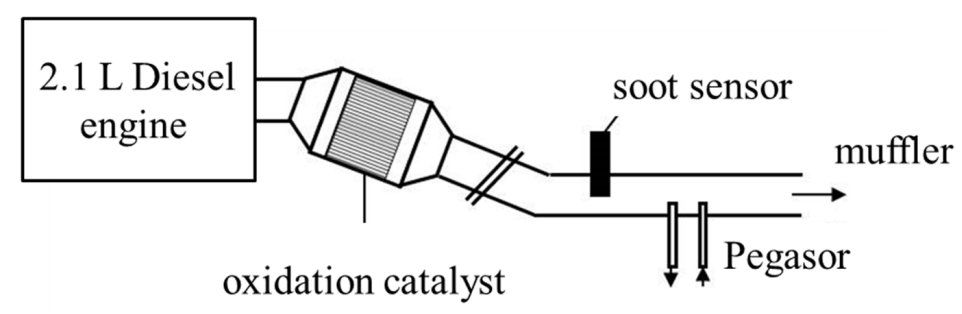

Figure 3. Setup for real exhaust measurements with a $2.1 \mathrm{~L}$ diesel engine.

To investigate the effect of soot deposition, the sensors were operated under constant exhaust conditions during the soot-collecting phase. A certain dc voltage was applied between the electrodes $\left(U_{\mathrm{IDE}}\right)$ and the resulting current $I$ was recorded. After that, soot regeneration was initiated by heating up the device. Regeneration leads to the well-known peak-shape in the current signal as shown in Figure 2 (and also for instance in [12,27,36]) followed by a zero current phase, when all soot is burned off. A new soot measurement cycle is then started. Within each engine operation point, at least three cycles were recorded unless otherwise stated in the respective section.

As a first step, dynamometer test at different engine operation points by varying the boost pressure to achieve different soot concentrations were conducted. One series included three sensor loading cycles, at three different soot concentrations, respectively. For each single measurement cycle, the sensor signal $\mathrm{d} I / \mathrm{d} t$ was calculated as a slope value in $\mathrm{mA} / \mathrm{s}$ (only the linear part of the $I(t)$-curve was taken to calculate the slope, as indicated in Figure 2). So, one measurement series provided nine data points, three for each soot concentration. These series were repeated several times at different days, with the dc voltage applied between the sensor electrodes being varied from 20 to $60 \mathrm{~V}$.

\section{Results and Discussion for Real Exhaust Measurements}

\subsection{Influence of the Applied Voltage/Electrophoresis}

In Figure 4, three typical and representative single sensor loading cycles under almost equal soot concentrations $\left(17 \mathrm{mg} / \mathrm{m}^{3}\right)$ are shown. The voltage between the IDEs $U_{\text {IDE }}$ was varied. The data are shifted to a joint starting time $t=0$, which is the end of the previous regeneration procedure. The raw data $I(t)$ already show the described effect: a higher voltage leads to a higher slope of the current. At first glance, one would attribute this to the higher voltage that drives a higher current in agreement with Ohm's law. However, the (calculated) conductance curves $\left(G=I / U_{\mathrm{IDE}}\right)$ still show the same behavior: the higher the voltage, the higher the slope of the conductance $\mathrm{d} G / \mathrm{d} t$. In other words, the soot deposition rate is in fact influenced by the applied voltage and one may assume that the amount of deposited soot on the sensor surface increases with the applied voltage. The data shown here are taken with a sensor oriented with electrodes facing the gas flow, but the findings are very similar for the opposite mounting. 


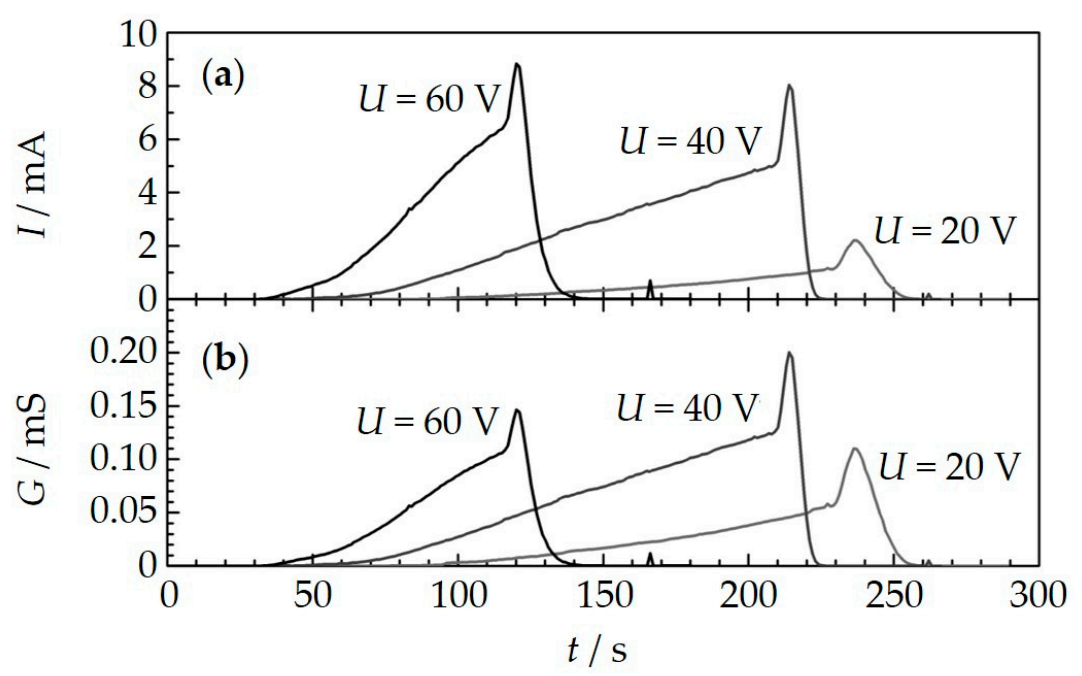

Figure 4. Raw data $I(t)((\mathbf{a})$ and calculated conductance data $G(\mathbf{b})$ for three measurement cycles (soot collection with different voltages and subsequent regeneration) under similar conditions (soot concentration $=17 \mathrm{mg} / \mathrm{m}^{3}$ ). The curves are shifted to a common starting time that is the end of the prior regeneration phase.

The percolation time (or blind time) also varies with the applied voltage and supports the previous findings. It can be determined directly from the current and/or the conductance curves. For lower applied voltages, the blind time until a first current appears increases. It takes nearly $100 \mathrm{~s}$ for $20 \mathrm{~V}$ and just $40 \mathrm{~s}$ for $60 \mathrm{~V}$ until the first current flows. Hence, higher voltages support the formation of conducting paths between the electrodes.

The effect of electrical field-supported soot deposition is well known. Soot particles from exhausts are electrically charged and are be attracted to the electrodes by a potential difference in such setups [38-43]. Detailed information on the charging of soot particles and electrophoresis are given in [50].

Figure 5 shows the sensor calibration curves, which include the timely derivatives of the conductance $\mathrm{d} G / \mathrm{d} t$ of a measurement cycle for each point plotted over the soot concentration measured by the Pegasor sensing device (values given in $\mathrm{mg} / \mathrm{m}^{3}$ ). Monotonous correlations between $\mathrm{d} G / \mathrm{d} t$ and soot concentrations are found for both types of sensor orientation. Furthermore, the provided conductance data are normalized to a common temperature of $300{ }^{\circ} \mathrm{C}$. Higher voltages result in a higher sensor signal. All these findings agree with the literature [35].
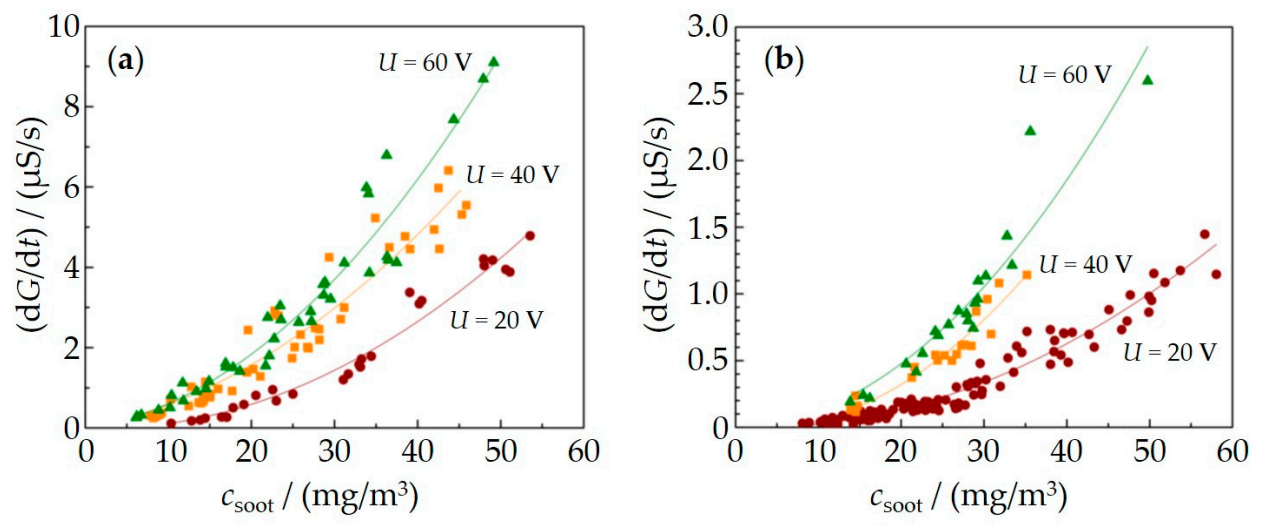

Figure 5. Sensor calibration curves (calculated conductance $d G / d t$ vs. soot concentration) for different types of sensor orientation in the exhaust, either IDE facing the gas flow (a) or in the opposite mounting position (b). 
The normalization was carried out by a linear calibration curve of the temperature dependency of the conductance. For that purpose, a sensor was operated in the exhaust and soot was deposited for $150 \mathrm{~s}$ at $U=60 \mathrm{~V}$. This produced a typical soot layer on the electrodes. The sensor was then taken out of the exhaust. Using the internal heater, temperatures between $150{ }^{\circ} \mathrm{C}$ and $375{ }^{\circ} \mathrm{C}$ were adjusted and the conductances were measured for 20,40 , and $60 \mathrm{~V}$, respectively. In all experiments, a temperature dependency of $\mathrm{d} G / \mathrm{d} T$ of ca. $0.3 \mu \mathrm{S} /{ }^{\circ} \mathrm{C}$ was found.

To obtain higher sensor signals and a reduced percolation time, electrophoresis has to be increased by a higher voltage. This causes an interesting phenomenon that is described in the following section.

\subsection{Influence of Thermophoresis}

In Figure 6a (upper graph), raw data of the conductance for three measurement cycles with subsequent regeneration for applied voltages between the interdigital electrodes of $60,40,20 \mathrm{~V}$ are shown. The engine operation point and, therefore, both the exhaust temperature and the soot concentration $\left(30 \mathrm{mg} / \mathrm{m}^{3}\right)$ were kept constant during the experiment. According to thermocouple data, the exhaust temperature varied only in a range of $\pm 5 \mathrm{~K}$. The increasing part of the conductance is of special interest here (area highlighted by a dashed ellipse). As already known from Figure 3, the slope of the conductance curve increases with increasing voltages and first percolation paths occur faster. Astonishingly, for $60 \mathrm{~V}$, the slope decreases, at least in the second half of the soot deposition period, whereas for $40 \mathrm{~V}$ and for $20 \mathrm{~V}$ the slope remains constant.

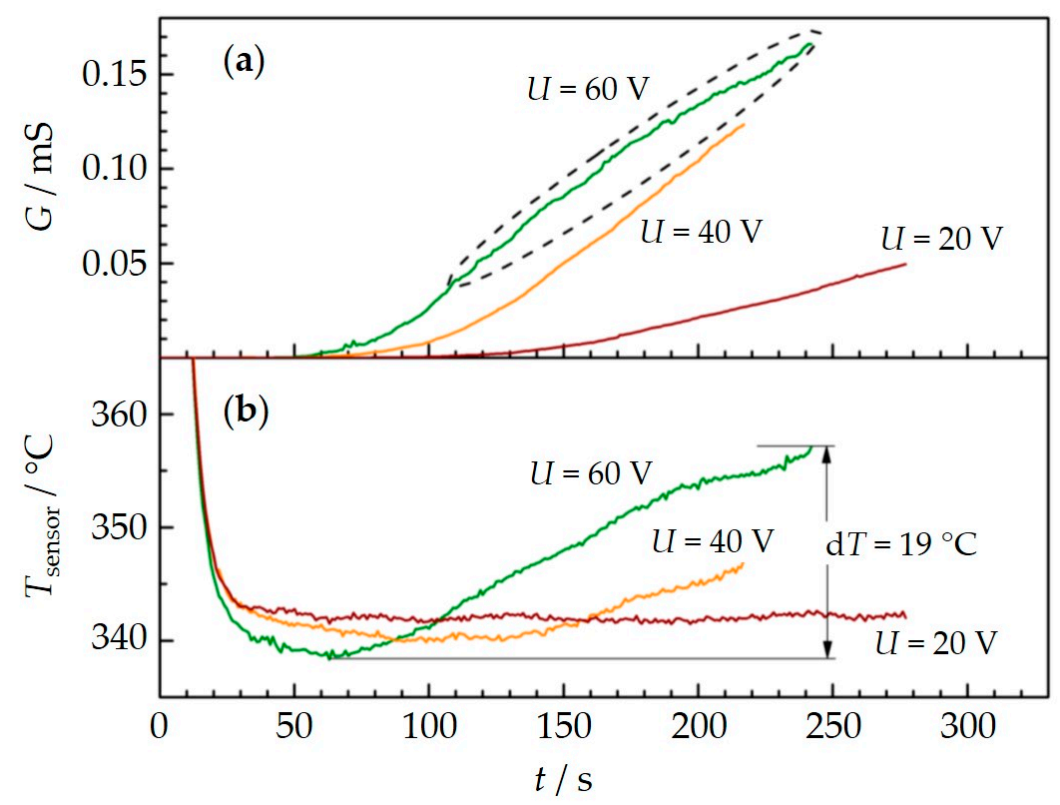

Figure 6. Conductance over time during soot deposition for three cycles with different voltages $U_{\text {IDE }}$ between the sensing electrodes (a) and corresponding sensor temperature determined by the reverse side platinum meander element $(\mathbf{b})$. The engine operation point was kept constant during the experiment (soot concentration $=30 \mathrm{mg} / \mathrm{m}^{3}$ ).

The respective temperature of the sensor element, which was measured by the internal heater structure during the whole experiment, is plotted in Figure 6b. In general, this temperature represents the exhaust temperature. Considering the temperature at 50 s, i.e., after sufficient cooling from regeneration temperature, one finds that the operation conditions are relatively constant and the exhaust temperature varies only in the range of $5^{\circ} \mathrm{C}$. The eye-catching result in this diagram is the increase of the sensor temperature during soot deposition for $60 \mathrm{~V}$ of about $19{ }^{\circ} \mathrm{C}$. When $40 \mathrm{~V}$ are applied for soot deposition, the sensor temperature increases a little less but still by $9{ }^{\circ} \mathrm{C}$. 
No temperature increase can be seen for $U_{\mathrm{IDE}}=20 \mathrm{~V}$. This suggests that a temperature increase of the sensor is responsible for the decreasing slope of the conductance in Figure 6a.

Since a temperature increase of the exhaust gas can be ruled out, an internal heating effect must be responsible for the observed behavior. If one calculates the power $P_{\mathrm{IDE}}\left(P=U_{\mathrm{IDE}} \cdot I=U_{\mathrm{IDE}}{ }^{2} \cdot G\right)$ that generates Joule's heat between the sensing electrodes and plots it vs the observed temperature increase, one obtains Figure 7 (for $U_{\mathrm{IDE}}=60 \mathrm{~V}$ ). In other words, during soot deposition, the power $P$, which generates heat directly in the deposited soot, increases. At the beginning, the conductance $G$ is zero since no current flows. Since there is no additional power $P$, there is no temperature increase. The higher the soot loading between the IDE, the higher is the conductance and the more heat is generated. At the end after $250 \mathrm{~s}$, a temperature increase of $19 \mathrm{~K}$ occurs. According to Figure 7, applying $60 \mathrm{~V}$ between the electrodes leads then to a heat generation of $0.6 \mathrm{~W}$. If we compare that with our experiences concerning the heater structure, materials data and simulations on similar sensor setups [51], an increase of $19 \mathrm{~K}$ seems plausible. As a conclusion, the temperature increase with higher applied voltages has a direct and an indirect origin. Due to the higher voltage, the soot deposition rate is higher due to the electrophoretic effect. This causes thicker soot layers that lead to a higher conductance of the soot films. In addition, the generated heat increases quadratically with the voltage.

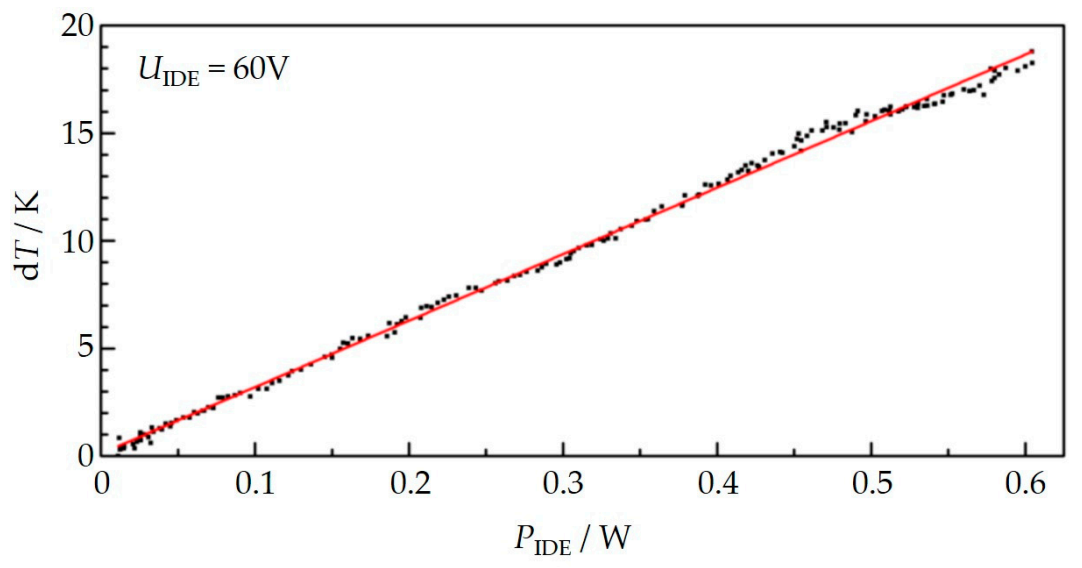

Figure 7. Internal self-heating of the device: Correlation of the increase of the sensor temperature (determined from the resistance of the platinum structure) and the calculated electrical power on the sensing electrodes during soot deposition when $60 \mathrm{~V}$ were applied, calculated from the data in Figure 6.

Therefore, we conclude that the internally generated heat reduces the rate of particulate matter deposition on the sensor surface due to thermophoresis [26,52,53], in other words, internally generated thermophoresis counteracts electrophoresis. This would explain the decreasing slope in the conductance curve as it has been found out in Figure 5 a for $60 \mathrm{~V}$.

Another experiment was conducted to investigate this "internally caused" thermophoresis effect further. Again, a sensor was constantly operated in the indirect mode with the heater structure facing the gas flow, now with $40 \mathrm{~V}$ applied between the electrodes. The engine was operated under constant speed and load. We conducted several soot deposition cycles, one after the other. After each regeneration procedure, the heater was not completely switched off, but set to a certain temperature. As a result, the sensor temperature $\left(T_{\text {sensor }}\right)$ during the soot deposition phase could be deliberately increased by small values, $\mathrm{d} T$, compared to the exhaust temperature ( $\left.T_{\text {exhaust }}\right)$. The sensor temperature was calculated from the four-wire resistance of the internal platinum structure. In the first cycle, no additional heating was applied $\left(\mathrm{d} T=T_{\text {sensor }}-T_{\text {exhaust }}=0 \mathrm{~K}\right)$. In the following cycles, the temperature was increased stepwise to $\mathrm{d} T=6,11,17,24$, and $33 \mathrm{~K}$. The results are shown in Figure 8. 


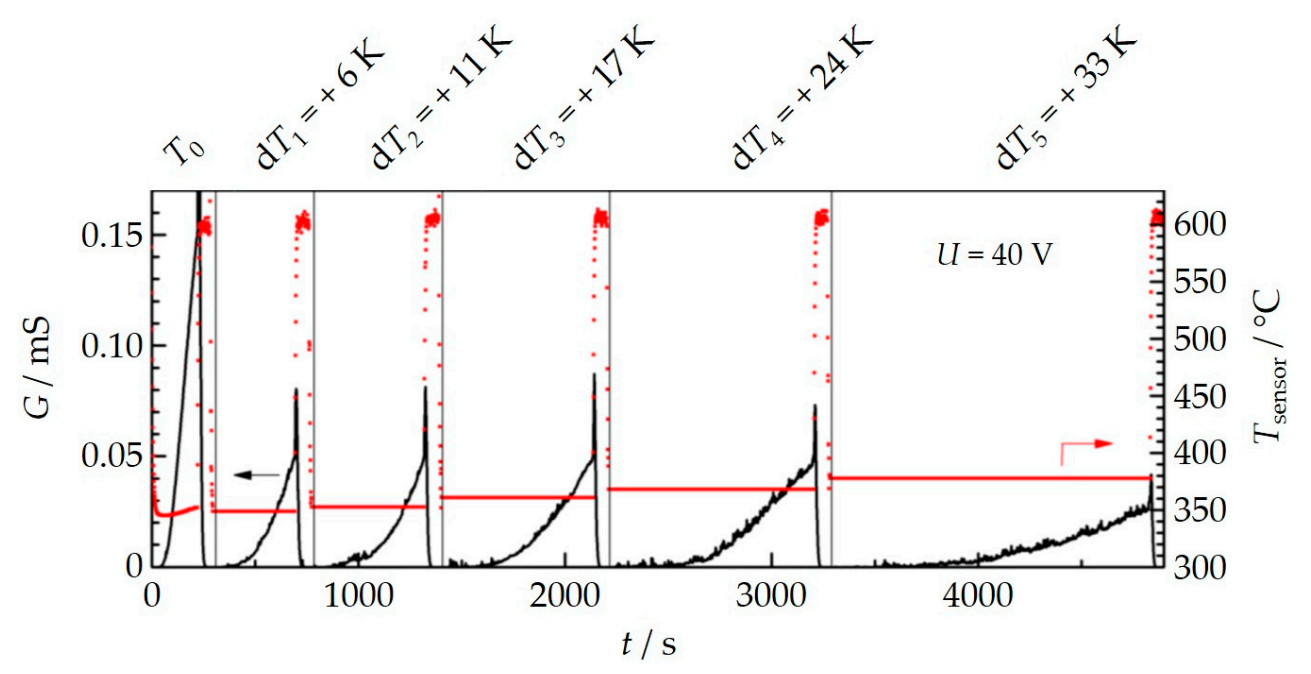

Figure 8. Conductance $G$ for several soot deposition cycles at $U_{\mathrm{IDE}}=40 \mathrm{~V}$ during constant engine operation. After regeneration, an additional small power was applied to the sensor to establish a slightly higher temperature of the sensor tip compared to the exhaust temperature. This temperature difference $\mathrm{d} T=T_{\text {sensor }}-T_{\text {exhaust }}$ that was kept constant during each soot deposition phase.

It turned out that the higher the sensor temperature is, the longer it takes until the first percolation sets in and the lower the slope of the conductance curve is during soot deposition.

In Figure $9 \mathrm{a}$, the slopes of the conductance $\mathrm{d} G / \mathrm{d} t$, as they were derived from Figure 8 , are plotted over the temperature difference $d T$. Since $d G / d t$ is a measure for the amount of soot that gets deposited on the sensor per time interval, the monotonously decreasing curve supports the assumption that "internally caused" thermophoresis is an effect that has to be considered when deducing soot concentrations from the slope of the conductance $\mathrm{d} G / \mathrm{d} t$.

In addition to that, this assumption was verified by another analysis. During regeneration, the current and correspondingly the conductance shows a "peak" behavior. The step change in sensor temperature up to $600^{\circ} \mathrm{C}$ leads to an almost sudden conductance increase due to the enhanced soot conductivity, followed by an abrupt decline when the soot gets oxidized and percolation is interrupted. The conductance reaches zero as soon as the soot is burned off. This behavior is well known and often described in literature $[12,27,36]$. The area below the peak of the conductance curve during regeneration may be correlated to the amount of soot that has been deposited right before the regeneration starts as both effects, the increasing conductance as well as the declining curve, depend on the thickness of the soot layer or its mass, respectively. In case of less deposited soot, the increasing part of the peak during heating up is smaller (less influence of temperature dependent conductivity increase). Furthermore, the declining part of the peak starts faster (less amount will be burned off earlier). Therefore, the peak area is small. Analogously, a higher amount of soot causes a higher current increase, the total oxidation takes longer and as a result, the peak area is larger. So, it should be possible to estimate the final soot loading (i.e., the amount of deposited soot mass) on the sensor surface before regeneration by evaluation of the peak area. We now plot these integral values of the conductance curve during regeneration vs. the temperature difference during soot deposition. Since not only the parameters $T_{\text {sensor }}$ or the applied voltage $U_{\text {IDE }}$ determine the amount of soot on the sensor surface, but also the individual time intervals for soot deposition for each single measurement, we have to normalize the integral value results to a similar time span of soot deposition to compare different measurement/regeneration cycles. This is done by the linear relation of conductance over time for each measurement cycle. All values refer now to a soot loading interval of $220 \mathrm{~s}$. Figure $9 \mathrm{~b}$ shows the correlation of the normalized integral values vs. $d T$. Here also, the exponential decrease occurs with very similar parameters as found before $(\exp (-0.3 x))$. Therefore, the evaluation of the peak area during regeneration can be used as an additional indicator of the amount of deposited soot right before regeneration. This method helps to understand thermophoresis effects when using 
synthetic soot (e.g., from CAST devices). Here, the conductivity of the soot does not linearly increase with temperature. Therefore, the conductance data are not sufficient to describe the amount of deposited soot [54].
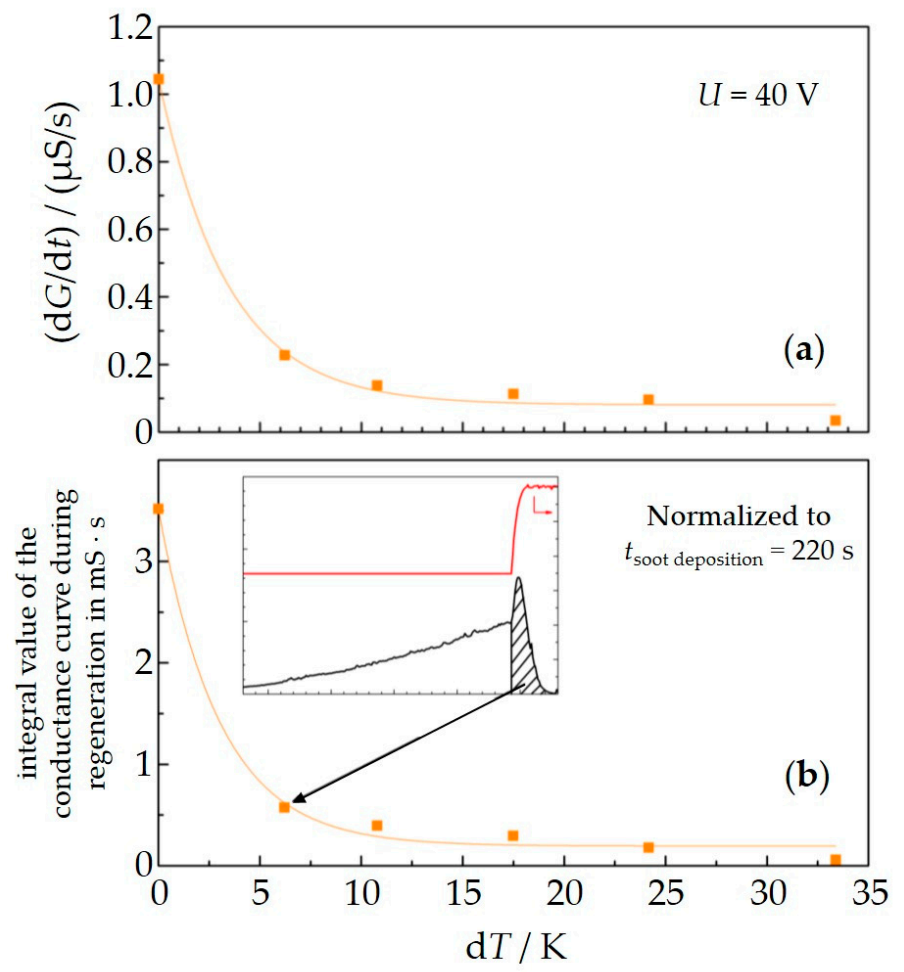

Figure 9. Slope of the conductance $\mathrm{d} G / \mathrm{d} t$ (evaluated from the data in Figure 8) vs. temperature difference between sensor and exhaust gas $\mathrm{d} T$ (a). The normalized integral values of the conductance curve during regeneration show similar behavior $(\mathbf{b})$. The inset shows the calculation for the integral value exemplarily.

In conclusion, thermophoresis strongly affects the rate of soot deposition on the sensor device. Whereas a higher voltage applied between the electrodes enhances soot deposition due to electrophoresis, a higher sensor temperature (which might be also caused by the applied high voltages between the electrodes) favors thermophoresis.

This effect might also be practically used. It should be possible to "adjust" the measurement ranges of soot sensors. Very fine electrode structures, for example, which allow detection of ultra-low soot concentrations (easy and fast path building) might be operated at higher temperatures in case of atmospheres with high amounts of soot.

\section{Conclusions and Outlook}

The present contribution considered the effect of different voltages that generate different electrical fields to support the attraction of soot particles to enhance the deposition on the surface of planar conductometric soot sensors. In contrast to other studies, we carefully investigated the effect of internal heating of the soot due to higher applied voltages. The internally caused thermophoresis is an effect that hinders the application of higher voltages between the electrodes in conductometric soot sensors. Both mechanisms occur in real exhausts as well as in synthetic conditions; the results coincide in general. However, using synthetic soot causes some challenges which should be discussed in a separate paper.

Advantageously, these parameters might be used to influence directly and knowledge-based the soot deposition or interaction with a sensor device. This could help to adjust even the sensitivity of soot sensors and its use in different atmospheres with varying soot concentrations. 
As a future goal, we intend to develop soot sensors that are sensitive to certain soot fractions. Therefore, ongoing work will focus on lab measurements with defined particle fractions. Variations will be necessary also concerning the IDE geometry or its layout, the mounting position, or even the sensor principle. The possibilities of influencing soot adsorption by the device's operation strategy (voltage and temperature) might be adaptable to "select" defined soot fractions, e.g., to discriminate between different soot fractions. Here, the exhaust gas temperature and the exhaust velocity should be taken into account. Recently published investigations on modeling particle deposition mechanisms [55] indicate an influence of these parameters on the question of whether electrophoresis or thermophoresis plays the major role.

Author Contributions: G.H. and R.M. designed the experiments; C.S., M.F. and A.M. performed the experiments; C.S. analyzed and evaluated the data; J.K. manufactured the sensor devices; G.H. and R.M. wrote the paper.

Acknowledgments: The publication of this paper was funded by the German Research Foundation (DFG) and the University of Bayreuth in the funding program "Open Access Publishing".

Conflicts of Interest: The authors declare no conflict of interest.

\section{References}

1. Maricq, M. Chemical characterization of particulate emissions from diesel engines: A review. J. Aerosol Sci. 2007, 38, 1079-1118. [CrossRef]

2. Twigg, M.V.; Phillips, P.R. Cleaning the Air We Breathe-Controlling Diesel Particulate Emissions from Passenger Cars. Platin. Met. Rev. 2009, 53, 27-34. [CrossRef]

3. Alkemade, U.; Schumann, B. Engines and Exhaust after Treatment Systems for Future Automotive Applications. Solid State Ion. 2006, 177, 2291-2296. [CrossRef]

4. Franco, V.; Kousoulidou, M.; Muntean, M.; Ntziachristos, L.; Hausberger, S.; Dilara, P. Road vehicle emission factors development: A review. Atmos. Environ. 2013, 70, 84-97. [CrossRef]

5. Burtscher, H.; Majewski, W.A.; Jääskeläinen, H. PM Measurement: In-Situ Methods. DieselNet 2014, 7, 1-25.

6. Mohr, M.; Lehmann, U.; Rütter, J. Comparison of Mass-Based and Non-Mass-Based Particle Measurement Systems for Ultra-Low Emissions from Automotive Sources. Environ. Sci. Technol. 2005, 39, 2229-2238. [CrossRef] [PubMed]

7. Harris, S.J.; Maricq, M. Signature Size Distributions for Diesel and Gasoline Engine Exhaust Particulate Matter. J. Aerosol Sci. 2001, 32, 749-764. [CrossRef]

8. Kittelson, D.B. Engines and Nanoparticles: A Review. J. Aerosol Sci. 1998, 29, 575-588. [CrossRef]

9. Guan, B.; Reggie, Z.; He, L.; Huang, Z. Review of the state-of-the-art of exhaust particulate filter technology in internal combustion engines. J. Environ. Manag. 2015, 154, 225-258. [CrossRef] [PubMed]

10. Weigl, M.; Roduner, C.; Lauer, T. Particulate Filter Onboard Diagnostics by Means of a Particulate Sensor. In Proceedings of the FISITA 2010 World Automotive Congress, Budapest, Hungary, 30 May-4 June 2010.

11. Brunel, O.; Duault, F.; Lavy, J.; Creff, Y.; Youssef, B. Smart Soot Sensor for Particulate Filter OBD. SAE Int. J. Passeng. Cars Electron. Electr. Syst. 2013, 6, 307-327. [CrossRef]

12. Kamimoto, T. A review of soot sensors considered for on-board diagnostics application. Int. J. Eng. Res. 2016, 18, 631-641. [CrossRef]

13. Uchiyama, T.; Fujie, H.; Aso, M. DPF Failure Detection Method and DPF Failure Detection Device. U.S. Patent 8,770,016 B2, 20 December 2012.

14. DieselNet, On-Board Diagnostics. Available online: https://www.dieselnet.com/standards/us/obd.php (accessed on 21 February 2018).

15. Johnson, T. Review of Diesel Emissions and Control. SAE Int. J. Fuels Lubr. 2010, 3, 16-29. [CrossRef]

16. Rose, D.; Boger, T. Different Approaches to Soot Estimation as Key Requirement for DPF Applications. SAE Tech. Pap. 2009, 2009. [CrossRef]

17. Sappok, A.; Bromberg, L. Loading and Regeneration Analysis of a Diesel Particulate Filter with a Radio Frequency-Based Sensor. SAE Tech. Pap. 2010, 2010. [CrossRef]

18. Feulner, M.; Hagen, G.; Piontkowski, A.; Müller, A.; Fischerauer, G.; Brüggemann, D.; Moos, R. In-Operation Monitoring of the Soot Load of Diesel Particulate Filters-Initial Tests. Top. Catal. 2013, 56, 483-488. [CrossRef] 
19. Feulner, M.; Hagen, G.; Hottner, K.; Redel, S.; Müller, A.; Moos, R. Comparative Study of Different Methods for Soot Sensing and Filter Monitoring in Diesel Exhausts. Sensors 2017, 17, 400. [CrossRef] [PubMed]

20. Husted, H.; Roth, G.; Nelson, S.; Hocken, L.; Fulks, G.; Racine, D. Sensing of Particulate Matter for on-Board Diagnosis of Particulate Filters. SAE Int. J. Eng. 2012, 5, 235-247. [CrossRef]

21. Rostedt, A.; Marjamäki, M.; Yli-Ojanperä, J.; Keskinen, J.; Janka, K.; Niemelä, V.; Ukkonen, A. Non-Collecting Electrical Sensor for Particle Concentration Measurement. Aerosol Air Q. Res. 2009, 9, 470-477. [CrossRef]

22. Reiß, S. Continental ePM sensor for detecting particle emission. In Proceedings of the 3rd International Conference Sensors for Exhaust Gas Cleaning and $\mathrm{CO}_{2}$ Reduction, Leipzig, Germany, 29-30 June 2016.

23. Kondo, A.; Yokoi, S.; Sakurai, T.; Nishikawa, S.; Egami, T.; Tokuda, M.; Sakuma, T. New Particulate Matter Sensor for On Board Diagnosis. SAE Int. J. Eng. 2011, 4, 117-125. [CrossRef]

24. Hagen, G.; Feulner, M.; Werner, R.; Schubert, M.; Müller, A.; Rieß, G.; Brüggemann, D.; Moos, R. Capacitive soot sensor for diesel exhausts. Sens. Actuators B Chem. 2016, 236, 1020-1027. [CrossRef]

25. Wasisto, H.S.; Merzsch, S.; Uhde, E.; Waag, A.; Peiner, E. Partially Integrated Cantilever-Based Airborne Nanoparticle Detector for Continuous Carbon Aerosol Mass Concentration Monitoring. J. Sens. Sens. Syst. 2015, 4, 111-123. [CrossRef]

26. Malik, A.; Abdulhamid, H.; Pagels, J.; Rissler, J.; Lindskog, M.; Nilsson, P.; Bjorklund, R.; Jozsa, P.; Visser, J.; Spetz, A.; et al. A Potential Soot Mass Determination Method from Resistivity Measurement of Thermophoretically Deposited Soot. Aerosol Sci. Technol. 2011, 45, 284-294. [CrossRef]

27. Masoudi, M.; Sappok, A.G. Soot (PM) Sensors. DieselNet 2014, 7, 1-14.

28. Ochs, T.; Schittenhelm, H.; Genssle, A.; Kamp, B. Particulate Matter Sensor for On Board Diagnostics (OBD) of Diesel Particulate Filters (DPF). SAE Int. J. Fuels Lubr. 2010, 3, 61-69. [CrossRef]

29. Bartscherer, P.; Moos, R. Improvement of the Sensitivity of a Conductometric Soot Sensor by Adding a Conductive Cover Layer. J. Sens. Sens. Syst. 2013, 2, 95-102. [CrossRef]

30. Hagen, G.; Feistkorn, C.; Wiegärtner, S.; Heinrich, A.; Brüggemann, D.; Moos, R. Conductometric Soot Sensor for Automotive Exhausts: Initial Studies. Sensors 2010, 10, 1589-1598. [CrossRef] [PubMed]

31. Lloyd Spetz, A.; Huotari, J.; Bur, C.; Bjorklund, R.; Lappalainen, J.; Jantunen, H.; Schütze, A.; Andersson, M. Chemical sensor systems for emission control from combustions. Sens. Actuators B Chem. 2013, 187, 184-190. [CrossRef]

32. Grob, B.; Schmid, J.; Ivleva, N.P.; Niessner, R. Conductivity for Soot Sensing: Possibilities and Limitations. Anal. Chem. 2012, 84, 3586-3592. [CrossRef] [PubMed]

33. Fleischer, M.; Pohle, R.; Wiesner, K.; Meixner, H. Soot sensor for exhaust gase. In Proceedings of the Eurosensors XIX, Barcelona, Spain, 11-14 September 2005.

34. Wiegärtner, S.; Hagen, G.; Kita, J.; Reitmeier, W.; Hien, M.; Grass, P.; Moos, R. Thermoelectric hydrocarbon sensor in thick-film technology for on-board-diagnostics of a diesel oxidation catalyst. Sens. Actuators B Chem. 2015, 214, 234-240. [CrossRef]

35. Hagen, G.; Müller, A.; Feulner, M.; Schott, A.; Zöllner, C.; Brüggemann, D.; Moos, R. Determination of the Soot Mass by Conductometric Soot Sensors. Procedia Eng. 2014, 87, 244-247. [CrossRef]

36. Feulner, M.; Hagen, G.; Müller, A.; Schott, A.; Zöllner, C.; Brüggemann, D.; Moos, R. Conductometric Sensor for Soot Mass Flow Detection in Exhausts of Internal Combustion Engines. Sensors 2015, 15, 28796-28806. [CrossRef] [PubMed]

37. Marr, I.; Groß, A.; Moos, R. Overview on Conductometric Solid-State Gas Dosimeters. J. Sens. Sens. Syst. 2014, 3, 29-46. [CrossRef]

38. Grondin, D.; Breuil, P.; Viricelle, J.P.; Vernoux, P. Development of a particulate matter sensor for diesel engine. Procedia Eng. 2015, 120, 1237-1240. [CrossRef]

39. Grondin, D.; Geara, S.; Breuil, P.; Viricelle, J.P.; Vernoux, P. Influence of Electrodes Polarization on the Response of Resistive Soot Sensor. Procedia Eng. 2016, 168, 31-34. [CrossRef]

40. Grondin, D.; Westermann, A.; Breuil, P.; Viricelle, J.P.; Vernoux, P. Influence of key parameters on the response of a resistive soot sensor. Sens. Actuators B Chem. 2016, 236, 1036-1043. [CrossRef]

41. Kittelson, D.B.; Pui, D.Y.H.; Moon, K.C. Electrostatic Collection of Diesel Particles. SAE Tech. Pap. 1986, 19-30. [CrossRef]

42. Maricq, M. On the electrical charge of motor vehicle exhaust particles. Aerosol Sci. 2006, 37, 858-874. [CrossRef] 
43. Bilby, D.; Kubinski, D.J.; Maricq, M. Current amplification in an electrostatic trap by soot dendrite growth and fragmentation: Application to soot sensors. J. Aerosol Sci. 2016, 98, 41-58. [CrossRef]

44. Burtscher, H. Physical Characterization of Particulate Emissions from Diesel Engines: A Review. J. Aerosol Sci. 2005, 36, 896-932. [CrossRef]

45. Dunne, L.J.; Sarkar, A.K.; Kroto, H.W.; Munn, J.; Kathirgamanathan, P.; Heinen, U.; Fernandez, J.; Hare, J.; Reid, D.G.; Clark, A.D. Electrical, Magnetic and Structural Characterization of Fullerene Soots. J. Phys. Condens. Matter 1996, 8, 2127-2141. [CrossRef]

46. Sielicki, P.; Janik, H.; Guzman, A.; Namieśnik, J. Grain Type and Size of Particulate Matter from Diesel Vehicle Exhausts Analysed by Transmission Electron Microscopy. Environ. Technol. 2012, 33, 1781-1788. [CrossRef] [PubMed]

47. Huffman, G.P.; Huggins, F.E.; Shah, N.; Huggins, R.; Linak, W.P.; Miller, C.A.; Pugmire, R.J.; Meuzelaar, H.L.; Seehra, M.S.; Manivannan, A. Characterization of Fine Particulate Matter Produced by Combustion of Residual Fuel Oil. J. Air Waste Manag. Assoc. 2000, 50, 1106-1114. [CrossRef] [PubMed]

48. Luo, C.H.; Lee, W.M.; Liaw, J.J. Morphological and Semi-Quantitative Characteristics of Diesel Soot Agglomerates Emitted from Commercial Vehicles and a Dynamometer. J. Environ. Sci. 2009, 21, $452-457$. [CrossRef]

49. Monahan, P. Cleaning Up Diesel Pollution: Emissions from Off-Highway Engines by State; Union of Concerned Scientists: Cambridge, MA, USA, 2003.

50. Krinke, T.J.; Deppert, K.; Magnusson, M.H.; Schmidt, F.; Fissan, H. Microscopic Aspects of the Deposition of Nanoparticles from the Gas Phase. J. Aerosol Sci. 2002, 33, 1341-1359. [CrossRef]

51. Ritter, T.; Wiegärtner, S.; Hagen, G.; Moos, R. Simulation of a thermoelectric gas sensor that determines hydrocarbon concentrations in exhausts and the light-off temperature of catalyst materials. J. Sens. Sens. Syst. 2017, 6, 395-405. [CrossRef]

52. Messerer, A.; Niessner, R.; Pöschl, U. Thermophoretic Deposition of Soot Aerosol Particles under Experimental Conditions Relevant for Modern Diesel Engine Exhaust Gas Systems. J. Aerosol Sci. 2003, 34, 1009-1021. [CrossRef]

53. Lutic, D.; Pagels, J.; Bjorklund, R.; Josza, P.; Visser, J.H.; Grant, A.W.; Johansson, M.L.; Paaso, J.; Fägerman, P.-E.; Sanati, M.; et al. Detection of Soot Using a Resistivity Sensor Device Employing Thermophoretic Particle Deposition. J. Sens. 2010, 2010, 421072. [CrossRef]

54. Hagen, G.; Spannbauer, C.; Moos, R. Electrophoretic and thermophoretic effects on conductometric soot sensing: Special challenges when using synthetic soot. In Proceedings of the 17th International Meeting on Chemical Sensors (IMCS 17), Vienna, Austria, 15-19 July 2018. [CrossRef]

55. Fragkiadoulakis, P.; Geivanidis, S.; Samaras, Z. Modeling a resistive soot sensor by particle deposition mechanisms. J. Aerosol Sci. 2018, 123, 76-90. [CrossRef] 